\title{
Analysis and Design Aspects of Support Measures of Main Caverns of Karuma Hydropower Project, Uganda
}

\author{
B K Ojha \\ Ex-Project Director, EIPL
}

\begin{abstract}
The Power house complex of Karuma Hydropower project comprises three main caverns i.e Power house, Transformer Hall and Tailrace surge gallery set at a depth of about $80 \mathrm{~m}$ in mainly granitic gneiss rock medium. The cavern has been oriented in a $N 141^{\circ}$ direction based on engineering considerations. The principle stress direction is also found nearly parallel to the axis of the caverns and thus the present orientation satisfies both engineering and geotechnical criteria. The support by way of rock anchors and SFRS/ Plain shotcrete has been provided based on analysis using phase 2 software. The underground caverns lie in low geostress field and therefore numerical simulation of excavation of these caverns were done to understand the rock mass behavior during excavation and thus help in design of excavation sequence and rock support. The excavation of all three caverns has since been completed and concrete works are in progress. This paper sums up the 3D simulation analysis of the rock medium and the proposed rock support system for the three caverns.
\end{abstract}

\section{Introduction}

The Karuma Hydropower project is a run of the river scheme located on Nile river in the Northern district about $270 \mathrm{Km}$ of Kampala, the capital city of Republic of Uganda. The project envisages the construction of $14 \mathrm{~m}$ high concrete dam, $6 \mathrm{nos}, 20 \mathrm{~m}$ high tower type power intake and $7.7 \mathrm{~m}$ diameter headrace tunnel to carry 1048 cumecs of design discharge to feed 6x 100MW of Francis turbines- generators to generate $600 \mathrm{MW}$ of power. The power house complex consist of three parallel large caverns i.e. $200 \mathrm{~m}(\mathrm{~L}) \mathrm{x} 21.3 \mathrm{~m}(\mathrm{w}) \mathrm{x}$ $53 \mathrm{~m}(\mathrm{H})$ - Power house cavern, $161 \mathrm{~m}(\mathrm{~L}) \times 14.7 \mathrm{~m}(\mathrm{~W}) \times 18.5 / 32.50 \mathrm{~m}(\mathrm{H})$ transformer cavern and $314 \mathrm{~m}(\mathrm{~L}) \mathrm{x}$ $21.50 \mathrm{~m}(\mathrm{~W}) \times 50 \mathrm{~m}(\mathrm{H})$ twin restricted orifice type tailrace surge chamber. The water is taken back to the river through $12.9 \mathrm{~m}$ finished diameter, bottom flat horse shoe shaped and $8.6 \mathrm{Km}$ and $8.7 \mathrm{Km}$ long twin tail race tunnels. The rock bolt crane girder has been designed for the EOT crane beam in view of good rock mass condition. The reinforced concrete beam of the Rock bolt crane girder is anchored to the rock wall of the power house cavern with bolts so that the loads are jointly shared by the RCC, bolts and surrounding rocks. The Power House Complex is hardly $200 \mathrm{~m}$ away from the river bank and is housed in a shallow rock cover. Excavations of these three caverns have been completed through granitic gneiss and the geological features encountered have been on expected lines. The layout of the power house complex is shown in Fig 1 longitudinal section along the power house complex is furnished in Fig 2.

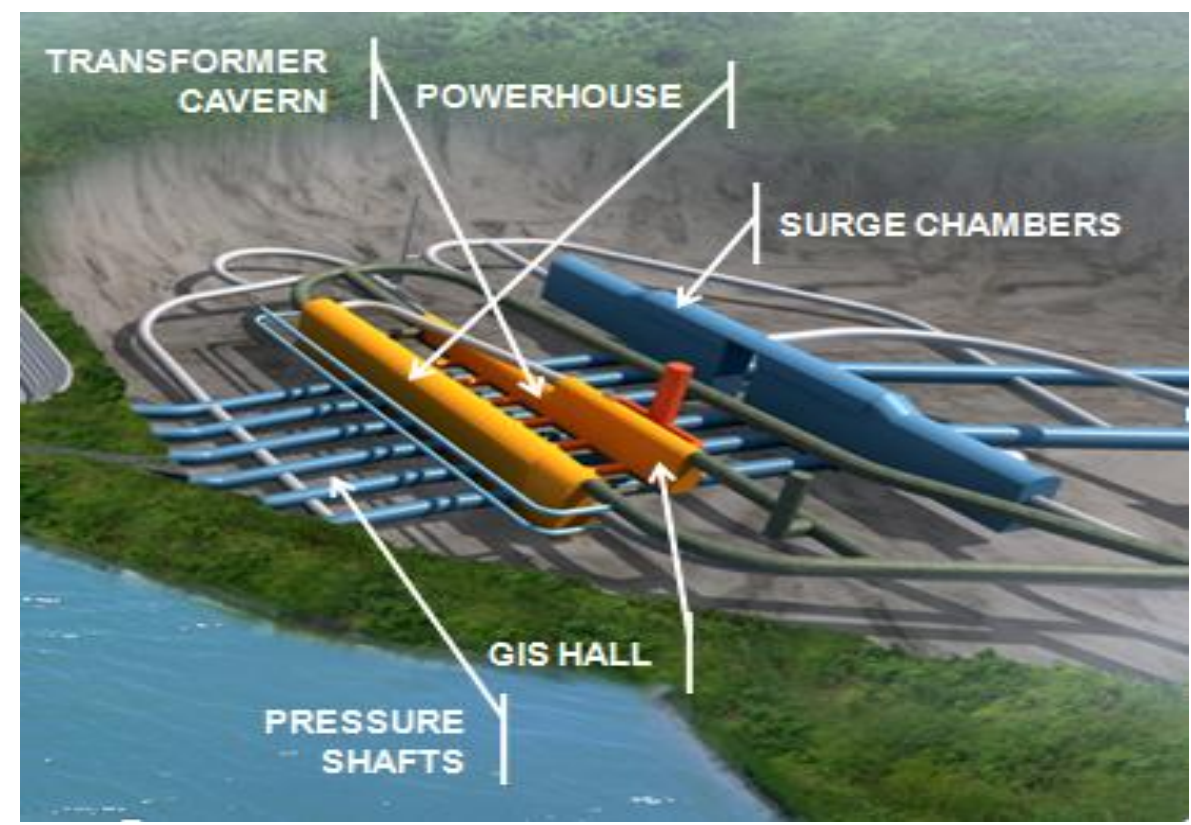

Fig 1: Layout of Power House Complex 


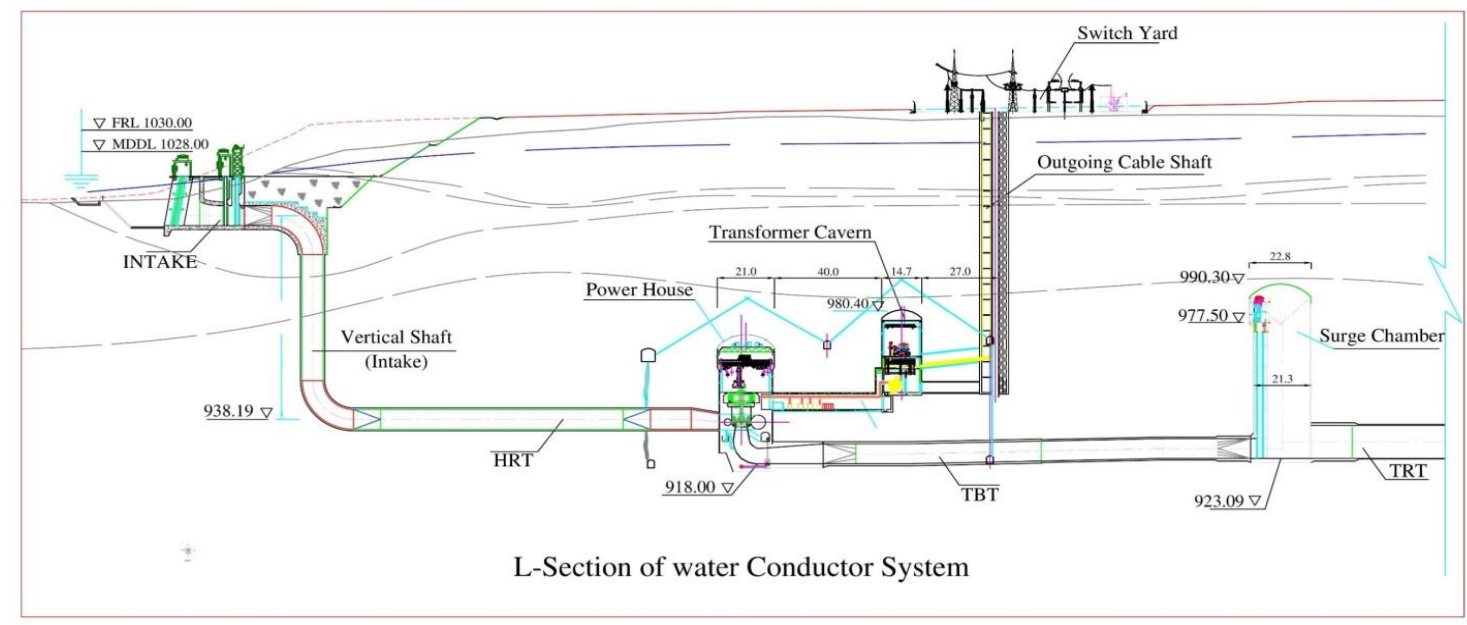

Fig 2

\section{Geological Set-up}

The rock type exposed in the project site comprise of granite gneiss including biotite gneiss amphibolites gneiss and amphibolites. The exploration of the rock mass around power house was done by excavating drift and drill holes. The surrounding rocks in the underground powerhouse site is slightly weathered granitic gneiss, amphibolite gneiss, and amphibolites with integrated rock mass, the tendency of the gneissic schistosity is substantially perpendicular to the cavern axis. The underground powerhouse mainly is in class II rock class and the caverns is very stable as a whole.

The rock mass is dissected by four sets of geological discontinuities. The four set of joints developed are:

- $\quad$ S1 (Foliation Joint) with altitude $125-140^{\circ} / 75-80^{\circ}$, persistence is very high $(720 \mathrm{~m})$, with spacing 2 to $6 \mathrm{~m}$.

- S2: with altitude $160-175^{\circ} 55-70^{\circ}$ persistence is low to medium $(2-5 \mathrm{~m})$, with spacing 0.5 to $0.6 \mathrm{~m}$

- S3: with altitude $340-355^{\circ} / 75-85^{\circ}$, persistence is high $(>20 \mathrm{~m})$, with spacing 0.5 to 0.6

- S4 with altitude $005-015^{\circ} 55-70^{\circ}$, persistence is low $(1-3 \mathrm{~m})$ and is discontinuous developed, with 0.5 to $3 \mathrm{~m}$.

The joints are tight and are rough planar. However it is found that four sets of joints do not appear at the same place and 1 or 2 sets of joints appear within the same section.

\section{Cavern Orientation}

The underground complex has been designed with power house transformer cavern and twin tailrace surge gallery with depth of cover in the range of $80 \mathrm{~m}$ from the surface. These caverns are parallel to each other with 40m of rock pillar between power house and Transformer cavern and $119 \mathrm{~m}$ between Transformer cavern and Tail Race Surge Chamber. Main consideration in orienting the cavern is to make longitudinal axis perpendicular to the strikes of the faults and joints are parallel to the direction of the maximum rock stress and at the same time to ensure that the layout fits well with the orientation of the water conductor system. In the present case the caverns have been oriented $\mathrm{N} 39^{\circ} \mathrm{W}-\mathrm{S} 39^{\circ} \mathrm{E}$ tentatively in line with the geotechnical consideration and matching the layout of the water conductor system. The thickness of the overlaying rock mass on the underground powerhouse and transformer room is about $40-50 \mathrm{~m}$ (1.9 to 2.38 times of the cavern diameter), while that on the tailrace surge chamber is about $32-44 \mathrm{~m}$ ( 1.52 to 2 times of the cavern diameter), which can basically meet the requirements of the 1.5 to 2.0 times of overlying rock mass thickness. According to the engineering experience, because of less rock cover, proper precaution is required on the excavation sequence and rock support measures as well as monitoring of the rock deformation.

The gneissesity attitude of power house is $\mathrm{N} 35-50^{\circ} \mathrm{E} \mathrm{SE}<75-80^{\circ}$ and the welding between gneissosity is firm. The underground powerhouse axis has an angle of $64 \sim 90{ }^{\circ}$ with the foliation strike, which is favorable for the excavation of underground caverns.

There is an angle of $34 \sim 41^{\circ}$ between the joints of $\mathrm{N} 78 \sim 88^{\circ} \mathrm{W} \mathrm{NE}<75 \sim 85^{\circ}$ and the cavern axis strike. The joints of $\mathrm{N} 15 \sim 33^{\circ} \mathrm{W} \mathrm{NE}<75 \sim 85^{\circ}$ is approximately parallel to the cavern axis but have no influence on the stability of cavern roof, because the two sets of joints are usually closed and steep- dip. The joints of $\mathrm{N}$ $73 \sim 82^{\circ} \mathrm{W} \mathrm{SW}<45 \sim 65^{\circ}$ and foliation with moderate- dip angle are easy to form unstable random block at the roof with random joints, so the systematic support is provided.

In the side wall, there is an angle of $64 \sim 90^{\circ}$ between the powerhouse axis and foliation strike, while the dip angle is mainly $10 \sim 30^{\circ}$. The foliation is easy to form unstable blocks with random joints on sidewall, and hence systematic support measure are provided The structural plane stereographic projection result is shown in Fig 3 . 

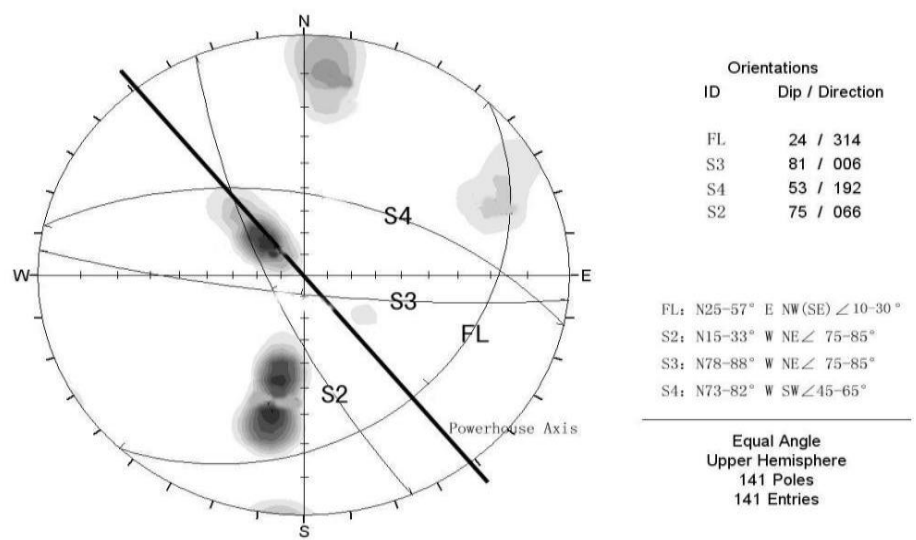

Fig 3. Stereographic projection of powerhouse sidewall

During the excavation it was observed that the lithology is mainly slightly newly weathered granitic gneiss intercalated with a small amount of biotite gneiss and amphibole gneiss. The rock is hard and rock mass is intact to relatively intact. The RQD is ranging from $85-95 \%$. Generally $1-2$ sets of structural planes are developed with close combination in between. Weathering condition is generally unweathered to slightly weathered. Ground condition is dry to damp. The RMR values vary between $65 \sim 72$ and Q value ranging from 14-28 and thus rock mass is generally of class II. However in a length of $10 \mathrm{~m}$ at RD $152 \sim 142$, where the rock mass condition is fair(class-III) with RMR value 41 and Q value 0.92 . In this stretch a shear zone of thickness $0.5-0.7 \mathrm{~m}$ is exposed along foliation with attitude $118-122^{\circ} / 63-69^{\circ}$. Maximum thickness of fault is $0.85 \mathrm{~m}$, filling is white plagioclase with crushed rock blocks and a little sand and gravel. The fault is exposed on the crown area and on the downstream wall but no trace of fault is found on the upstream wall in the 2ndbench excavation. A patch of Amphibolite $18-20 \mathrm{~m}$ wide is present from RD $0+00 \mathrm{~m}$ to $0+20 \mathrm{~m}$ encountered in the $2 \mathrm{nd}$ bench excavation. In this stretch although the rock mass conditions are good (class-II) but the area is moderately to highly jointed and orientation of these joints facilitated the plane and wedge failures in the excavation of slant portion for crane beam.

\section{In-situ Stress}

The In-situ stress is a key input parameter in understanding the rock mass behavior and in design of rock support for the caverns. Analyses carried out by way of numerical models indicate that the rock behavior is influenced significantly by the state of in-situ stress especially the horizontal to vertical stress ratio. The values obtained from the hydro fracturing tests conducted in the two exploratory drill holes in power house indicated

a) Maximum horizontal principle stress as 3.05 8.89 Mpa

b) Minimum horizontal principal stress $2.63 \sim 6.23 \mathrm{Mpa}$

c) Direction of maximum horizontal principal stress $\mathrm{N} 55^{\circ}-62^{\circ} \mathrm{E}$ which is almost parallel to the rock mass gneissosity.

The stress measurements are identically consistent with the regional stress field and the horizontal tectonic stress is dominant in underground powerhouse area. The horizontal stress ratio is about 0.71-0.82 and the maximum horizontal principal stress is in the direction of $\mathrm{N}^{\circ} 6^{\circ}-\mathrm{N} 60^{\circ}$ and thus the power house complex belongs to the low-stress area. The strength-stress ratio is 4.7-6.9, more than 4 and thus the in-situ stress has an exiguity influence on the surrounding rock. During the excavation of caverns no high geostress problems such as rock spalling and peeling off were observed which only indicates that the strength -stress ratio of surrounding rocks within the powerhouse area is relatively high and geostress has hardly an impact on the stability of surrounding rock mass.

\section{3d Simulation Analysis}

The numerical analysis using finite difference element FLAC3D was carried out considering the surrounding rocks around caverns as perfectly plastic, homogeneous and isotropic medium. The numerical study was based on the Mohr-Coulomb failure criterion which gives a very simple solution for the progressive failure of the rock mass surrounding the cavern. The numerical simulation was carried out to understand the deformation behavior of surrounding rock medium during excavation, the buckling failure mode of rocks mechanical behavior and thus assist in designing the rock support system for the caverns. Based on results of many field and laboratory tests combined with similar projects experiences following rock properties have been used in the analysis. 


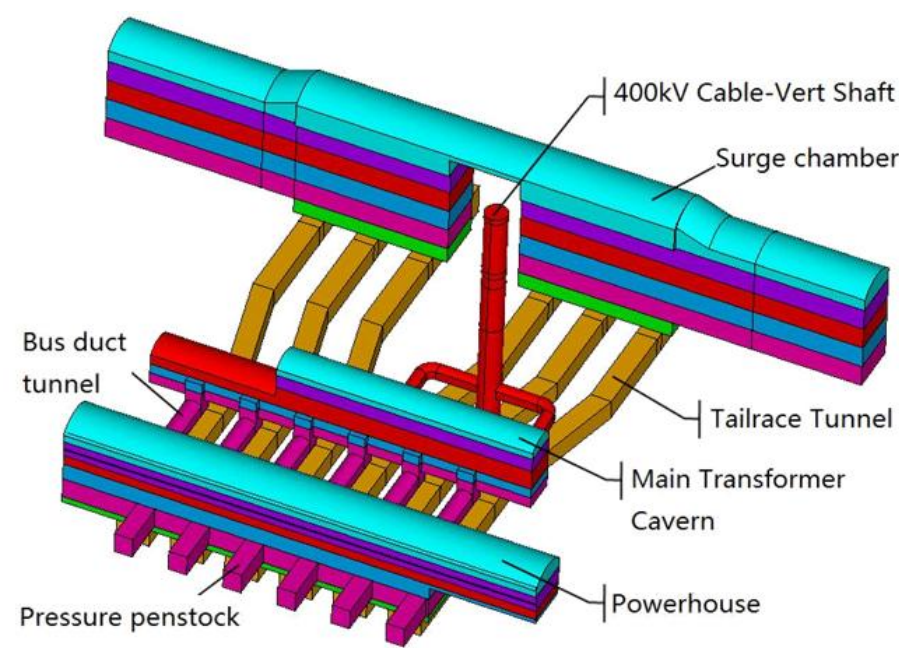

Fig 4. Model of underground Caverns

Table-1. Rock parameters

\begin{tabular}{|c|c|c|c|c|c|c|}
\hline \multirow{2}{*}{$\begin{array}{l}\text { Rock Mass } \\
\text { Classification }\end{array}$} & \multirow[t]{2}{*}{ Degree of Weathering } & \multirow{2}{*}{$\begin{array}{l}\text { Volume Weight } \\
\left(\mathrm{kN} / \mathrm{m}^{3}\right)\end{array}$} & \multirow{2}{*}{$\begin{array}{l}\text { Poisson } \\
\text { Ratio }\end{array}$} & \multirow{2}{*}{$\begin{array}{l}\text { Modulus of } \\
\text { Deformation } \\
\text { (Gpa) }\end{array}$} & \multicolumn{2}{|c|}{ Shearing Strength } \\
\hline & & & & & $\mathrm{f}^{\prime}$ & $\begin{array}{l}\mathrm{C}^{\prime} \\
(\mathrm{Mpa})\end{array}$ \\
\hline II & Slightly weathered or fresh & 26.5 & 0.185 & 14 & 1.15 & 1.6 \\
\hline III & $\begin{array}{l}\text { Lower section of moderately } \\
\text { weathered }\end{array}$ & 26 & 0.215 & 7 & 0.95 & 1.05 \\
\hline IV & Highly Weathered & 24 & 0.275 & 2 & 0.55 & 0.35 \\
\hline
\end{tabular}

The influence of stress contours of one cavern over others and to calculate stresses and displacements around underground excavations, the finite difference element was carried out on FLAC 3D to simulate the actual excavation process of underground caverns and obtain displacement, stress field and plastic zone during the stage wise excavation of surrounding rocks around powerhouse caverns and the result of analysis is furnished in table -2 The excavation responses for the powerhouses and the main transformer cavern are respectively analyzed as follows:

\subsection{Rock Mass Deformation}

Since the underground powerhouse is horizontal tectonic stress based and the rock cover being not very high, the sidewall deformation is greater than the crown arch deformation. After the cavern excavation, the maximum deformation of the powerhouse crown works to about $5 \mathrm{~mm}$ but increases to $12 \mathrm{~mm}$ in the main transformer cavern crown due to the caverns effect. The maximum deformation of the surge chamber cavern crown arch is about $6 \mathrm{~mm}$ and the cavern bottom floor indicates rebound relaxation deformation of about $12 \mathrm{~mm}$. The high sidewall effect is significant at the powerhouse cavern showing a deformation to the tune of 35 $40 \mathrm{~mm}$ in the upstream side wall and $40-50 \mathrm{~mm}$ in the downstream sidewall. . The sidewall deformation at the main transformer cavern is less than that at the powerhouse, with the maximum deformation of about $12 \sim$ $15 \mathrm{~mm}$. The maximum deformation of the powerhouse end wall is about $12 \sim 16 \mathrm{~mm}$, and the end wall displacement of the transformer cavern is about $8 \sim 12 \mathrm{~mm}$. The maximum deformation of upstream sidewall of surge chamber is about $35 \sim 40 \mathrm{~mm}$, and the maximum deformation of downstream sidewall is about 40 45mm.

The rock mass deformation was monitored in all the three caverns by way of 4-point Bore-hole extensometers. The instruments exhibited better rock mass behavior with maximum displacement of less than $3 \mathrm{~mm}$ in all the three caverns except the downstream wall near bus duct junction with a cumulative displacement of $6.69 \mathrm{~mm}$ during the excavation period.

\subsection{Rock Stress}

The rock stress field indicates significant changes after excavation. Since this zone is controlled by the regional horizontal tectonic stress field, the crown arch at the powerhouses, the main transformer cavern and surge chamber exhibits significant stress concentration with the maximum compressive stress of about 10 $12 \mathrm{MPa}$. The stress at the powerhouse machine hall reaches to the maximum compressive stress of about $15 \mathrm{MPa}$. As the large structural face nearby the caverns is absent and the stress relaxation at the surrounding caverns is uniformly distributed, the stress relaxation at upstream and downstream high sidewall is quite conspicuous with the minimum principal stress being in the range of about $1 \sim 3 \mathrm{MPa}$. 
Analysis and Design Aspects of Support Measures of Main Caverns of Karuma Hydropower ..

\subsection{Rock's Plastic Zone}

The thickness of rock pillar's plastic zone is much larger between the powerhouse and the main transformer cavern, but there are still large elastic rock pillars between the two. The thickness of rock pillar's plastic zone is very large between the main transformer cavern and surge chamber.

Analyzing the extent of surrounding rock's plastic zone distribution for the caverns after the excavations, powerhouse crown shows with plastic zone at an depth of $1 \sim 3 \mathrm{~m}$ where as the high side walls experiences rock's plastic zone up to a depth of about 4 8m . Main transformer cavern crown with plastic zone at a depth of $1 \sim$ $2 \mathrm{~m}$, the side wall rock is about $3 \sim 5 \mathrm{~m}$ depth. Surge chamber crown with plastic zone at an ordinary depth of $1 \sim$ $2 \mathrm{~m}$, the side wall rock in general is about $4 \sim 8 \mathrm{~m}$ depth.

The Response statistics of Underground caverns is furnished in Table-2

Table 2

\begin{tabular}{|l|l|l|l|l|}
\hline \multicolumn{2}{|l|}{$\begin{array}{l}\text { Cavern } \\
\text { Excavation response. }\end{array}$} & Power House & Transformer Cavern & Surge chamber \\
\hline \multirow{2}{*}{\begin{tabular}{l|l|l|} 
Deformation (mm) \\
Plastic Zone (m)
\end{tabular}} & Top Arch & 5 & 12 & 6 \\
\cline { 2 - 5 } & Si de Wall & $40 \sim 50$ & $12 \sim 15$ & $40 \sim 45$ \\
\hline $\begin{array}{l}\text { The first principal stress } \\
(\mathrm{MPa})\end{array}$ & Top Arch & $1 \sim 3$ & $1 \sim 2$ & $1 \sim 2$ \\
\cline { 2 - 5 } & Si de Wall & $4 \sim 8$ & $3 \sim 5$ & $4 \sim 8$ \\
\cline { 2 - 5 } $\begin{array}{l}\text { The third Principal stress } \\
(\mathrm{MPa})\end{array}$ & Si de Wall & $-8 \sim-12$ & $-6 \sim-8$ & $-6 \sim-10$ \\
\cline { 2 - 5 } & Top Arch & $-2 \sim-4$ & $-2 \sim-4$ & $-1 \sim-2$ \\
\hline
\end{tabular}

The buried depth of the caverns has been shallow and vertical geostress is small. Controlled by the horizontal principle stress, the rock mass of the cavern crown arch has good stability. The high sidewall effect is dominant at the main power house and tailrace surge cavern but the local tensile stress has not exceeded the rock tensile strength, and the relaxation depth of the side wall is relatively higher and hence timely installation of support is paramount.

\section{Rock Support Measures}

The rock support system has been designed as per rock mass classification parameters and in line with the analysis of surrounding rock stability. The rock support measures for the three caverns were studied by 3D simulation analysis. As per the recommendations made by Grimstad and Barton (1993), the spacing, number and strength of rocks bolts and shotcrete thickness requirement depends on rock mass quality Q and span of the cavity as shown in fig-3. The permanent support in the form of rock anchors and shortcrete were proposed based on geological underground powerhouse of surrounding rock $Q$ value $=28$, cavern span 19.6m, Excavation support ratio $(\mathrm{ESR})=1.0$ as per Fig -5 below:

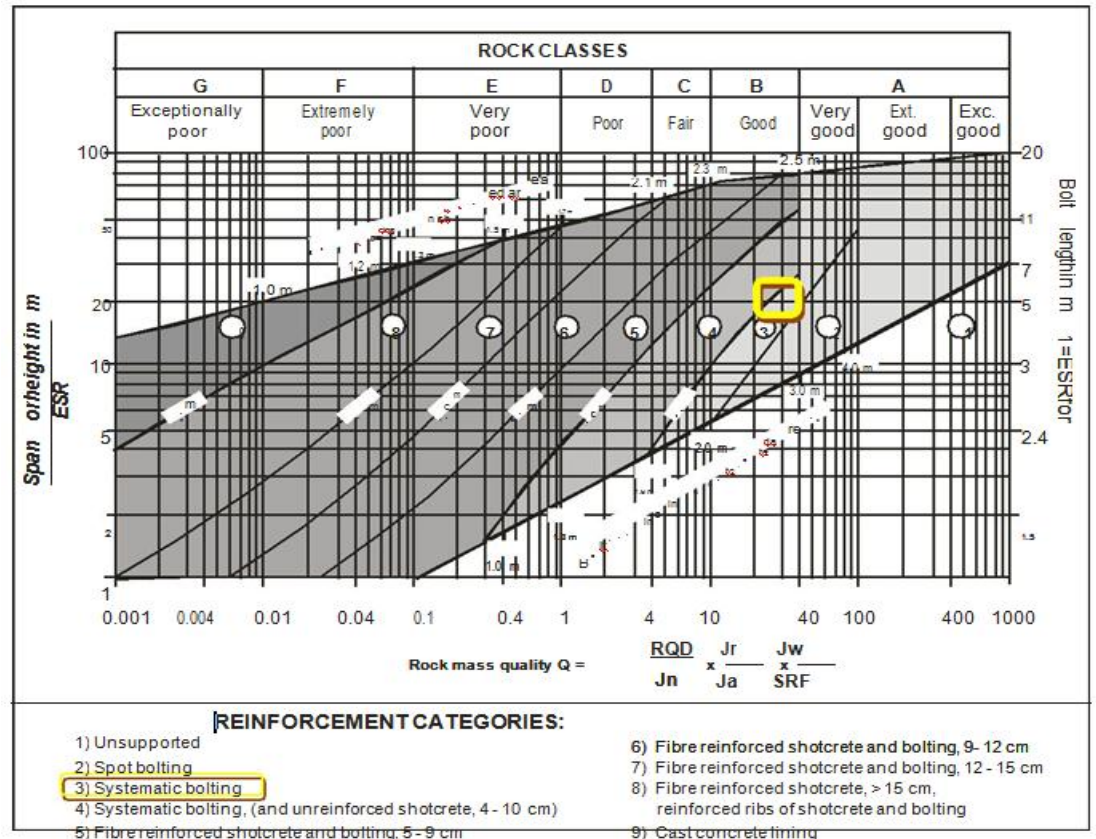

Fig 5: Q classification -Permanent Support Reccomendation (Grimstad\& Barton, 1993) 
Similarly for Transformer cavern with span $14.7 \mathrm{~m}$ and ESR=1.0, the corresponding support was worked out and for Tail Race Surge gallery with a span of $22.8 \mathrm{~m}$ and ESR=1.0,the corresponding support measures were calculated as shown in fig.3. Since the high side wall effect is significant in Surge Chamber and maximum displacement reaches $42 \mathrm{~mm}$ at the waist of side walls, the rock support design has been given due attention. The rock support as finalized for the three caverns is furnished in Table 3.

Table-3. Support measures for Caverns.

\begin{tabular}{|l|l|l|}
\hline Cavity & Roof & Walls \\
\hline & $\begin{array}{l}150 \mathrm{~mm} \text { thick SFRS and } 6 \mathrm{~m} \text { to } 9 \mathrm{~m} \text { long } 28 \mathrm{~mm} \\
\text { diameter grouted rock anchor @ } 1.5 \mathrm{~m} \mathrm{c} / \mathrm{c}\end{array}$ & $\begin{array}{l}150 \mathrm{~mm} \text { thick plain shotcrete, 25 diameter } 6 \mathrm{~m} / 9 \mathrm{~m} \\
\text { long grouted rock anchor @ } 1.50 \mathrm{mc} / \mathrm{c} .\end{array}$ \\
\hline $\begin{array}{l}\text { Pransformer cavern } \\
\text { Tail race surge } \\
\text { chamber }\end{array}$ & $\begin{array}{l}120 \mathrm{~mm} \text { thick shotcrete } 25 \text { diameter } 6 \mathrm{~m} \text { long } \\
\text { rock anchor cement grouted @ } 1.5 \mathrm{~m} \mathrm{c} / \mathrm{c} .\end{array}$ & $\begin{array}{l}120 \mathrm{~mm} \text { thick shortcrete } 25 \text { diameter } 6 \mathrm{~m} \text { long } \\
\text { rock anchor cement grouted @ } 1.5 \mathrm{~m} \mathrm{c} / \mathrm{c} .\end{array}$ \\
\hline
\end{tabular}

Since there shall be water level fluctuation in this Surge Chamber $40 \mathrm{~cm}$ thick reinforced concrete lining is being provided on the walls of the surge cavern. The rock anchors as provided in the side walls shall be connected with lining reinforcement mesh to provide additional safety of the wall. The caverns are being monitored by way of 4-point multi- point borehole extensometer (MPBX), anchor stress meters and these instruments have shown stable trend during the excavation process.

\section{Conclusion}

The orientation of the longer axes of the power house, transformer cavern and TRT surge chamber was finalized to suit the water conductor system and also meeting the requirement of the joint pattern and principal stress direction. The stability estimation by numerical analysis showed that the total displacements and yielding zones were drastically reduced after rock reinforcements. The rock mass and the geological discontinuities encountered in the caverns were on the predicted lines and excavation of the caverns has been completed and was a smooth affair. The instruments indicated rock mass deformations well within designed values.

\section{Acknowledgement}

The author is thankful to Ministry of Energy and Mineral Development (MEMD), UEGCL of Govt. of Uganda and Sinohydro, and Hydrochina Huadong Corporation, China for cooperation during fieldwork and for the studies and data compilation.

\section{Reference}

[1]. Basic Design Report and unpublished technical reports of Karuma HPP-Hydrochina Huadong corporation, China

[2]. GB 50287-2006: Code for hydropower engineering geological investigation, P R China.

[3]. EM1110-2-2901, Engineering design of Tunnels and Shafts in Rocks, May 1997 by US Army corps of Engineers.

[4]. Support of Underground Excavations in Hard rock by Evert Hoek.

[5]. Barton N; Lien R. and Lunde J. 1974. Engineering classification of Rock Mass for the Design of Tunnel Support. Journal of Rock Mechanics Volume 6.

[6]. Bieniawski Z T.1992. Design Methodology in Rock Engineering. Balkema, Rotterdam

[7]. PRC 2008. Specification for design of Hydraulic Tunnels, Electric power Industry Standards,

[8]. Grimstand, E; and Barton, N; Updating of the Q system for NMT, Proceedings of the International Symposium on sprayed Concrete Modern use of Wet Mix Sprayed Concrete for Underground Support, Fagernes, Norway, 1993.

[9]. Central Board of Irrigation and Power, Manual on Planning and Design of Hydraulic Tunnels, Publication no:178, New Delhi, 1984.

\section{Brajesh Kumar Ojha "FIE",}

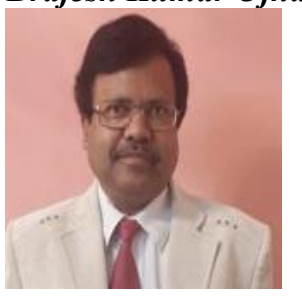

Graduated in Civil Engineering from Bhagalpur University Bihar in 1984 and joined National Hydro Electric Power Corporation (NHPC) a Govt. of India Enterprise in Feb 1985. He worked as Engineer to Chief Engineer in NHPC for more than 23 years. He has wide experience in design \& construction of Hydo-projects mainly being Teesta Stage V (510 MW) HE Project (NHPC) and Teesta Stage VI (500MW) HE Project( Lanco Infratech Limited) and Teesta III HE project (1200MW) in Sikkim. He has worked as Owner's Engineer(EIPL) for Govt. of Uganda for Karuma hydropower project (600MW) in North Uganda during 2015-16. He is a life member of Tunneling Association of India (TAI), INHA and ISRM and is a certified Chartered Engineer (India). He has more than twenty publications in national \& international journals and conferences. 